\title{
Prevalence of anaemia among pregnant women in rural India: a longitudinal observational study
}

\author{
Mishu Mangla ${ }^{1}$, Deepak Singla ${ }^{2}$ \\ ${ }^{1}$ Department of Obstetrics and Gynaecology, Gyan Sagar Medical College and Hospital, Banur, Punjab, India \\ ${ }^{2}$ Department of Anaesthesia, BPS Government Medical College, Khanpur-Kalan, Sonipat, Haryana, India
}

Received: 02 August 2016

Accepted: 02 September 2016

*Correspondence:

Dr. Deepak Singla,

E-mail: deepak10.4u@gmail.com

Copyright: $\odot$ the author(s), publisher and licensee Medip Academy. This is an open-access article distributed under the terms of the Creative Commons Attribution Non-Commercial License, which permits unrestricted non-commercial use, distribution, and reproduction in any medium, provided the original work is properly cited.

\begin{abstract}
Background: Anemia is a major public health problem affecting both the developed as well as the developing countries. According to World Health Organization, prevalence of anaemia among pregnant women in developed countries is about $14 \%$, whereas it is still as high as $51 \%$ in the developing world. The aim of the present study was to understand the health profile and the socio demographic factors of the country's rural pregnant females and to estimate the exact prevalence of anemia and its associated factors among pregnant women at term based on the level of hemoglobin.

Methods: This was a prospective, longitudinal cross sectional study. Hemoglobin estimates from pregnant females at term using antenatal care services or delivery services in a general hospital in a rural area of India, from September 2014 to March 2015 i.e. a period of 6 months, were obtained. The incidence of anemia and its associated socio demographic factors was studied. Although the overall prevalence of anaemia did not vary significantly with literacy level, the severity of anaemia differs to a great extent.

Results: The prevalence of anemia was 98\% among the pregnant females in this region of rural India. Out of these $41.76 \%$ had mild anemia, $37.05 \%$ had moderate anemia, $15.88 \%$ had severe anemia and $3.29 \%$ very severe anemia according to ICMR classification of anemia. The mean hemoglobin level was found to be 8.845 . The number of ANC visits in present pregnancy and whether the pregnant female had taken iron folic acid prophylaxis also were very significant variables in the determination of prevalence as well as the severity of anemia.

Conclusions: There is a significantly high prevalence of anaemia among pregnant women in rural areas of India. Our study has also enlisted a few socio demographic factors that contribute to such high prevalence of this disease. Programs focused on target population need to be planned and implemented with active participation of locals.
\end{abstract}

Keywords: Anemia, Socio demographic factors, Pregnancy at term

\section{INTRODUCTION}

Anemia is a major public health problem affecting both the developed as well as the developing countries. According to World Health Organization, prevalence of anaemia among pregnant women in developed countries is about $14 \%$, whereas it is still as high as $51 \%$ in the developing world. ${ }^{1}$ The condition is even worse in Southeast Asia. About half of all global maternal deaths due to anemia occur in South Asian countries, out of which India contributes to $80 \%{ }^{2}$
In India the prevalence of anaemia among pregnant women is about $65-75 \%$. $^{1}$

Anaemia has been known to be responsible for a number of maternal and foetal complications. Apart from decreasing the woman's reserve to tolerate bleeding either during or after child birth, it has been known to be associated with low birth weight, premature delivery, intra uterine growth retardation and thus increased perinatal mortality. ${ }^{3-6}$ Anaemia has also been found to be associated with increased risk of birth asphyxia and low. 
Apgar score at birth. ${ }^{7}$ A recent meta-analysis showed that the risk of maternal mortality decreases by $20 \%$ for every $1 \mathrm{~g} / \mathrm{dl}$ increase in the hemoglobin concentration. This decline is continuous between $\mathrm{Hb}$ levels between 5 and $12 \mathrm{mg} / \mathrm{dl}$ but not linear. ${ }^{8}$ Thus treating anaemia has major health implications in pregnancy and would go a long way in improving maternal and foetal outcome.

Despite the existing programs on prevention and control of anemia, such as Iron and folic acid supplementation and free supply of parenteral iron preparations, reports from multiple large national surveys indicate that there has been no significant decline in the prevalence of anemia or adverse consequences attributed to it. ${ }^{9-13}$ Often programs and projects aiming to prevent and control anemia are constrained by the erroneous data regarding socio economic profile of the target group and/or causative factors responsible for the same. So, the main objective of the present study was to understand the health profile and the sociodemographic factors of the country's rural pregnant women and to estimate the exact prevalence of anemia and other associated factors among pregnant women at term based on the level of hemoglobin.

\section{METHODS}

This longitudinal prospective observational study was conducted in the general hospital of a rural area of India. Gohana is the second largest town in district Sonipat with a total population of about $3,72,034$, out of which about $82.34 \%$ lives in rural areas ( as per census 2011). ${ }^{14}$

Pregnant women using antenatal care services at the general hospital from September 2014 to March 2015 i.e. a period of 6 months were taken as the source population. While the study population was women after 37 weeks of gestation who either visited the OPD for routine antenatal check-up or were admitted for delivery. We excluded women who were not term i.e. gestational age of less than 37 completed weeks, non-singleton pregnancies, with defined congenital malformations and maternal diabetes. With due administrative approval, 873 participants were thus enrolled in the study. The study participants were told about the purpose of the study and also the potential benefits that it may result in so as to help them make informed decision as to the participation in the study. They had also been informed that the participation is completely voluntary that they had the right to interrupt the interview or not to participate in the study at any stage. Then a written informed consent for participation in the study was obtained. Data pertaining to the various independent variables such as the socio-demographic factors, literacy levels, and number of visits for ante natal check-up was recorded. Details regarding their reproductive attributes such as gravidity, age at first pregnancy and birth interval were also sought. It was also asked whether or not they had taken iron and folic acid tablets during present pregnancy.
For determining anemia the outcome variable, each of the pregnant women enrolled in the study was advised to undergo hemoglobin estimation in the laboratory of the general hospital. Out of the study population a total of 23 women refused to undergo hemoglobin estimation and so were dropped from the study. Thus a total of 850 estimates of hemoglobin were obtained. Hemoglobin estimation was done by acid haematin method. All the hemoglobin estimations were performed by a single observer so as to eliminate inter observer variation. A Haemoglobin level of more than or equal to $11 \mathrm{mg} / \mathrm{dl}$ was considered as normal. Any women with a Hb level of less than $11 \mathrm{mg} / \mathrm{dl}$ was considered anemic. The levels of hemoglobin used for classification of anemia in pregnant women as mild, moderate and severe anaemia were those recommended by the Indian Council of Medical Research (ICMR). ${ }^{15}$ Mild, moderate and severe anemia was defined as follows:

- Mild anemia: Hb 10.0mg/dl-10.9 mg/dl.

- Moderate anemia: $\mathrm{Hb} 7.0 \mathrm{mg} / \mathrm{dl}-10.0 \mathrm{mg} / \mathrm{dl}$.

- Severe anemia: $\mathrm{Hb}$ less than $7 \mathrm{mg} / \mathrm{dl}$.

- Very severe anemia: Hb less than $4 \mathrm{mg} / \mathrm{dl}$

Data was analysed using SPSS® version 16 (Statistical Packages for the Social Sciences, Chicago, IL). Results were expressed as frequency and percentage. Quantitative data was compared using one-way analysis of variance (ANOVA) and unpaired t-test; qualitative data was analysed using Chi-square test.

\section{RESULTS}

A total of 850 study participants completed the study making a response rate of $97.36 \%$. The mean age of participants in this study was $26.17,21.5 \%$ of the females were illiterate, while $19.76 \%$ and $16.7 \%$ studied upto primary and secondary level respectively. Remaining $42.47 \%$ were graduates or post graduates. $25.52 \%$ were primigravida, $36.7 \%$ had one living child while $16.0 \%$ had more than 3 living children. As far as age at first pregnancy was concerned majority conceived at the age group of 19 to 24 years $(45.41 \%)$ for the first time. Majority had visited antenatal clinic during pregnancy (63.17\%), but only $27.64 \%$ had properly taken iron folic acid tablets.

The mean haemoglobin level was found to be 8.845 . Only $2 \%$ of the total pregnant female at term had hemoglobin above $11 \mathrm{mg} / \mathrm{dl}$. So, prevalence of anemia was $98 \%$ among the pregnant females in this region of rural Haryana. Out of these $41.76 \%$ had mild anemia, $37.05 \%$ had moderate anemia, $15.88 \%$ had severe anemia and $3.29 \%$ very severe anemia according to ICMR classification of anemia (Figure 1).

The prevalence of anemia in pregnant females in the age group 15-19 years was $95.4 \%$. Out of the total anemic women in this age group $64.6 \%$ had severe anemia, $12.3 \%$ had moderate anemia and remaining $64.6 \%$ had 
severe anaemia. However, no case of very severe anemia was found in this age group. Similarly majority of women in the age group 19-24 years $(86.04 \%)$ and $25-30$ years $(93.6 \%)$ had mild to moderate anemia. Whereas in women over the age of 30 years, the prevalence was of anaemia was $98.4 \%$. Among these, $10.4 \%$ had very severe anemia. The prevalence of moderate and severe anemia in this age group was $34.4 \%$ and $32.8 \%$ respectively.

Table 1: Socio-demographic or reproductive attributes of the study population.

\begin{tabular}{|c|c|c|c|c|c|c|}
\hline $\begin{array}{l}\text { Socio-demographic or } \\
\text { reproductive attribute }\end{array}$ & $\begin{array}{l}\text { All pregnant } \\
\text { women } \mathrm{N}= \\
850\end{array}$ & $\begin{array}{l}\text { No anemia } \\
\mathbf{N}=\mathbf{1 7}(\%)\end{array}$ & $\begin{array}{l}\text { Mild } \\
\text { anemia } \\
\text { N=355 (\%) }\end{array}$ & $\begin{array}{l}\text { Moderate } \\
\text { anemia } \\
\text { N=315 (\%) }\end{array}$ & $\begin{array}{l}\text { Severe } \\
\text { anemia } \\
\text { N=135 (\%) }\end{array}$ & $\begin{array}{l}\text { Very } \\
\text { severe } \\
\text { anemia } \\
\mathrm{N}=28(\%)\end{array}$ \\
\hline \multicolumn{7}{|l|}{ Age (years) } \\
\hline $15-19$ & $65(100.0)$ & $3(4.6)$ & $12(18.46)$ & $8(12.3)$ & $42(64.6)$ & $0(0.0)$ \\
\hline $20-24$ & 194 (100.0) & $4(2.1)$ & 119 (61.34) & $48(24.7)$ & $18(9.3)$ & $5(2.6)$ \\
\hline $25-29$ & 408 (100.0) & $7(1.7)$ & $186(45.6)$ & $196(48.0)$ & $15(3.7)$ & $4(1.0)$ \\
\hline$>30$ & $183(100.0)$ & $3(1.6)$ & $38(20.8)$ & $63(34.4)$ & $60(32.8)$ & $19(10.4)$ \\
\hline \multicolumn{7}{|l|}{ Education status } \\
\hline Illiterate & $179(100.0)$ & $2(1.1)$ & $41(22.9)$ & $57(31.8)$ & $53(29.6)$ & $26(14.5)$ \\
\hline Up to primary & $168(100.0)$ & $6(3.6)$ & $45(26.8)$ & $64(38.1)$ & $51(30.3)$ & $2(1.2)$ \\
\hline Up to secondary & $142(100.0)$ & $4(2.8)$ & $48(33.8)$ & $74(52.1)$ & $16(11.3)$ & $0(0.0)$ \\
\hline Graduate or post graduate & $361(100.0)$ & $5(1.4)$ & $221(61.2)$ & $120(33.2)$ & $15(4.15)$ & $0(0.0)$ \\
\hline \multicolumn{7}{|l|}{ Parity } \\
\hline 0 & $217(100.0)$ & $3(1.4)$ & $105(48.4)$ & $96(44.2)$ & $12(5.5)$ & $1(0.5)$ \\
\hline 1 & $312(100.0)$ & $4(1.3)$ & $168(53.8)$ & $131(42)$ & $4(1.3)$ & $5(1.6)$ \\
\hline 2 & $185(100.0)$ & $10(5.4)$ & $62(33.5)$ & $55(29.7)$ & $50(27.0)$ & $8(4.32)$ \\
\hline$\geq 3$ & $136(100.0)$ & $0(0.0)$ & $20(14.7)$ & $33(24.3)$ & $69(50.7)$ & $14(10.3)$ \\
\hline \multicolumn{7}{|l|}{ Age at first pregnancy } \\
\hline $15-19$ & $128(100.0)$ & $1(0.8)$ & $13(10.1)$ & 28 (21.9) & 66 (51.6) & 20 (15.6) \\
\hline $19-24$ & $386(100.0)$ & $8(2.1)$ & $158(41)$ & $177(45.8)$ & $39(10.1)$ & $4(1.0)$ \\
\hline $25-30$ & $300(100.0)$ & $5(11.6)$ & $174(58)$ & $98(32.7)$ & $20(6.6)$ & $3(1)$ \\
\hline$>30$ & $36(100.0)$ & $3(8.3)$ & $10(27.7)$ & $12(33.3)$ & $10(27.7)$ & $1(2.7)$ \\
\hline \multicolumn{7}{|c|}{ Interval since last delivery/ pregnancy outcome (years) } \\
\hline$<1$ & $309(100.0)$ & $0(0.0)$ & $87(28.1)$ & $128(41.4)$ & $72(23.3)$ & $22(7.11)$ \\
\hline $1-2$ & 259 (100.0) & $5(2)$ & $115(44.4)$ & $108(41.7)$ & 33 (12.7) & $3(1.1)$ \\
\hline $2-3$ & $268(100.0)$ & $5(1.9)$ & $204(76.1)$ & $39(14.5)$ & $19(7.1)$ & $1(0.4)$ \\
\hline$>3$ & $218(100.0)$ & $7(2.2)$ & $158(72.4)$ & $40(18.3)$ & $11(5.0)$ & $2(1)$ \\
\hline \multicolumn{7}{|c|}{ No. of ANC visits in present pregnancy } \\
\hline 1 or 2 & $537(100.0)$ & $2(0.4)$ & $276(51.4)$ & $142(26.4)$ & $92(17.1)$ & $25(4.6)$ \\
\hline 3or more & $126(100.0)$ & $3(2.4)$ & $7(5.5)$ & $78(61.9)$ & $38(30.1)$ & $4(3.2)$ \\
\hline $\begin{array}{l}\text { Regular/ as advised by } \\
\text { doctor }\end{array}$ & $187(100.0)$ & $12(6.4)$ & $75(40.1)$ & $75(40.1)$ & $95(50.8)$ & $0(0.0)$ \\
\hline \multicolumn{7}{|c|}{ IFA prophylaxis in present pregnancy } \\
\hline Nil & $248(100.0)$ & $0(0.0)$ & $86(34.7)$ & $55(22.2)$ & $88(35.5)$ & $19(7.6)$ \\
\hline Yes but not regular & $367(100.0)$ & $0(0.0)$ & $164(44.7)$ & $164(44.7)$ & $30(8.2)$ & $9(2.4)$ \\
\hline Regular & $235(100.0)$ & $17(7.2)$ & $105(44.7)$ & $96(40.8)$ & $17(7.2)$ & $0(0.0)$ \\
\hline
\end{tabular}

Although the overall prevalence of anemia did not vary significantly with literacy level, the severity of anemia differs to a great extent. $14.5 \%$ of total illiterate pregnant females had very severe anemia whereas no case of very severe anemia was found among graduates and post graduates. $61.2 \%$ of women educated up to graduate or post graduate levels had only mild anemia, 33.2 had moderate anemia and only $4.15 \%$ had severe anemia. The corresponding figures in the illiterate women were $22.9 \%, 31.8 \%$ and $29.6 \%$ respectively. Most women educated either upto primary and secondary level had mild (26.8 and $33.8 \%)$ or moderate anaemia (38.1 and 52.1\%) with prevalence of severe anaemia being $30.3 \%$ and $11.3 \%$ respectively. Only $1.2 \%$ women educated up to primary level had very severe anaemia. 


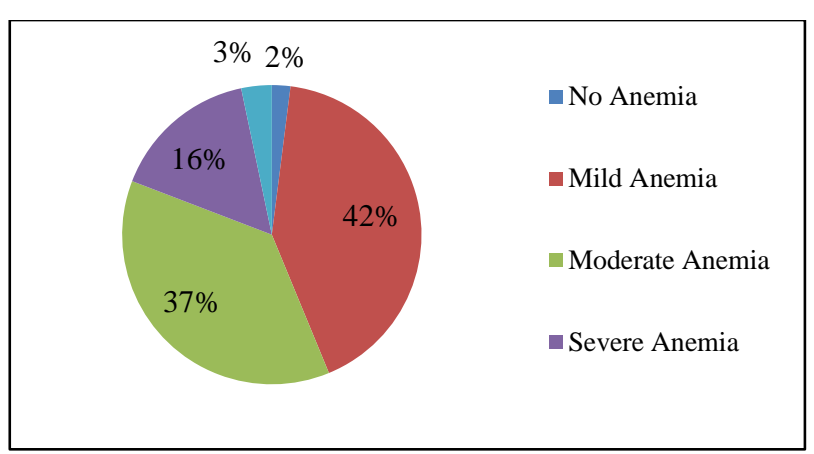

Figure 1: Prevalence of anemia among pregnant females.

Similarly, an inverse relation was found between the age at first pregnancy and prevalence and severity of anemia which showed significant decrease with increase in the age at first pregnancy (Table 1). Approximately $50 \%$ of the total cases of severe anemia and $72 \%$ of the total cases of very severe anemia were found in those females who had their first pregnancy below the age of 19 years (Figure 2).

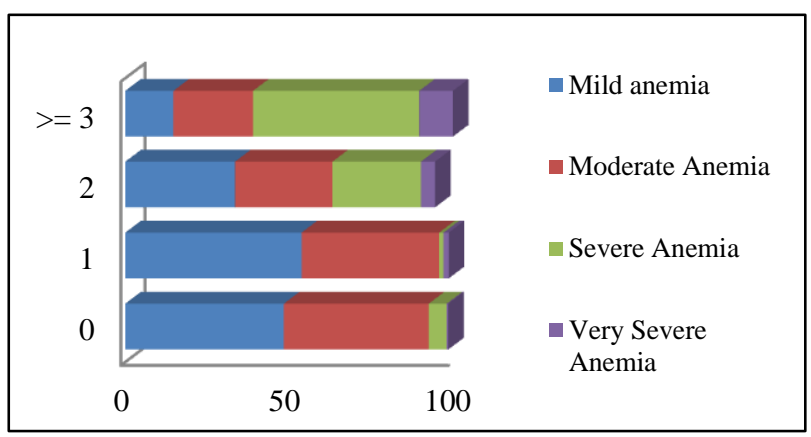

Figure 2: Relation between parity and prevalence and severity of anemia.

Similarly the parity of the pregnant female was also associated with the severity of anemia. $51.1 \%$ cases of severe anemia and $50 \%$ cases of very severe anemia were present in multiparous women. Majority of nulliparous or primiparous women had mild to moderate anemia. The interval since the woman's last delivery or any other pregnancy outcome was another variable which showed significant correlation between the presence and severity of anemia. $72.4 \%$ of pregnant females who had their last delivery or abortion 3 years or more prior to this pregnancy had mild anemia. Majority of cases of severe and very severe anemia were again found in females with a birth interval of less than 1 year (Figure 3). The number of ANC visits in present pregnancy and whether the pregnant female had taken Iron Folic acid prophylaxis also were very significant variables in the determination of prevalence as well as the severity of anemia. Majority of cases of Severe and very severe anemia were found in those pregnant females who had either not taken IFA prophylaxis or had taken it irregularly (100\%) and had underwent only1 or 2 ANC visits (89.3\%).

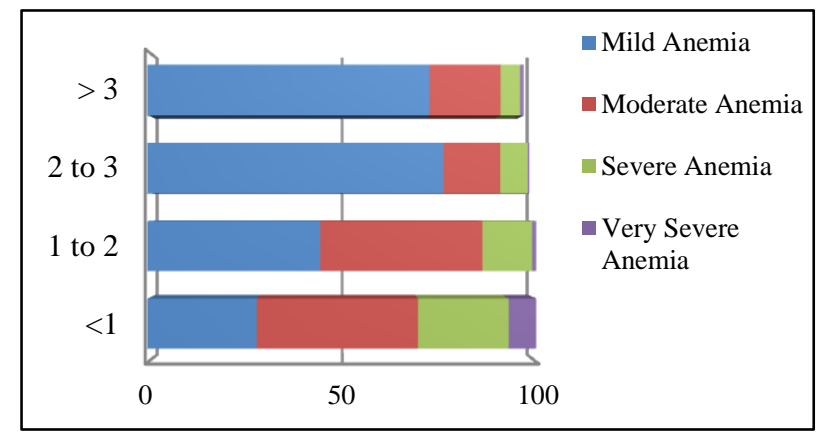

Figure 3: Relation between interval since last delivery/ pregnancy outcome and prevalence/ severity of anemia.

\section{DISCUSSION}

Considering Southeast Asia as a whole, India has the highest burden of anemia among pregnant women. In other parts of Southeast Asia, the prevalance in Bangladesh in 1981-82 was about $77 \%$ with no significant change in 1992. Indonesia and Nepal reported a prevalence of 63.5 and $65 \%$ respectively. ${ }^{16}$ It was $68 \%$ in Maldives, $58 \%$ in Myanmar and $60-70 \%$ in Sri-Lanka. Even though almost all parts of Southeast Asia have a high prevalence of anemia, the condition is worse in some rural areas especially in India. The reason for this inconsistency among different areas may be due to differences in socio-cultural, economic and geographical conditions.

In our study, we found a unusually high prevalence anemia (98\%) in rural Haryana. National Family Health Survey 2005-06 (NFHS- 3), showed Haryana to be second, only after Assam in terms of prevalence of anemia. ${ }^{11}$ Although NFHS -2 study showed a prevalence of as low as $55.5 \%$ for Haryana, a study conducted by Agarwal $\mathrm{K}$ et al found a very high prevalence of $91 \%$, similar to our study. ${ }^{9,17}$ A similar study conducted in rural Tamilnadu prevalence of anaemia was found to be $69.3 \%{ }^{15}$ Although, DLHS-3 survey had reported a prevalence as high as $97 \%$, with $41 \%$ of pregnant women having mild anemia, 53\% moderate and 3\% having severe anemia, a recent district level household and facility survey. 4 survey conducted in 2012-13 showed a prevalence of only $59.6 \%$ in Haryana, with rural areas showing slightly higher prevalence of $60.5 \% .^{13,18}$

Reasons for such high prevalence of anemia in rural Haryana may be diverse. The patriarchal nature of our society may be one of the major reasons responsible for such high prevalence of anemia. Discrimination against women right from birth in the form of availability of food and education may be considered an important cause. Similarly, women in rural areas rarely get to choose when they can marry, or regarding timings and spacing of child birth. Secondly, majority of women in our country are vegetarians. According to NFHS-3 survey, Haryana tops 
the list among these, with around $88 \%$ women being vegetarian. ${ }^{11}$ Meat, chicken and fish which happen to be a very rich source of iron are missing in vegetarian diets. Thirdly, due to poverty and lack of knowledge even vegetarian diet is rarely wholesome making dietary deficiencies even worse. Although the government has been providing food supplements to pregnant and lactating women under the Integrated Child Development Scheme (ICDS), only $21 \%$ of women in areas served by anganwadi workers, said, that they had ever received such supplements. ${ }^{11}$ Fourthly, though free ante-natal checkups and Iron and Folic acid tablets are provided to pregnant women, we found that only $22 \%$ of women got regular ANC checkups as advised by doctor and only $27.6 \%$ of pregnant females took 100 or more IFA tablets. According to DLHS -4 survey only $12.5 \%$ of women in rural Haryana get full ANC care and only $18.6 \%$ take 100 or more IFA tablets. ${ }^{18}$ These tablets are either not available widely or are not widely accepted among pregnant females, may be due to metallic taste and other side effects of oral iron. Lack of proper means of transport, poor condition of roads and inadequate medical facilities available in rural areas are some of the reasons for irregular ANC visits by pregnant patients. A better motivation by the front line health care workers such as ASHA's and anganwadi workers and proper counseling of pregnant women may thus help to improve the situation. Fifthly, poor hygiene and a high prevalence of diseases like hook worm may also be a contributing factor for anaemia.

In the present study we found a significant association between various socio demographic factors and the prevalence of anemia. A previous study by Kaur K has also found that socio-cultural factors play an important role in determining prevalence of anaemia. ${ }^{19} \mathrm{We}$ found that the severity of anemia was higher in women who were below 19 years or were more than 30 years of age. Both the prevalence as well as severity of anemia was more in illiterate women. A similar study from Mumbai also showed that younger age and schooling of atleast 10 years had any significant association with Haemoglobin levels. ${ }^{20}$ Thangeela et al conducted a similar study and found that prevalence of anemia was more below 20 and above 35 years of age. ${ }^{21}$ The impact of literacy status on anemia was also studied by Dutta et al and was found to be significant. ${ }^{22}$ Although some previous studies have found no significant correlation between age at first pregnancy and anemia. ${ }^{23,24}$ We found it to affect both the prevalence and severity of anemia significantly. Two other factors that significantly affect anemia in pregnancy are parity and the birth interval. A previous study has found that a birth interval of less than two years was a significant predictor of anemia $((88.9 \%$ Vs $65.3 \%, \chi 2=$ 4.3 at $\mathrm{df}=1, \mathrm{OR}=4.26$ with $95 \% \mathrm{CL}$ of 1.07 to 19.73$){ }^{24}$

Our study had certain limitations. Firstly, only patients coming to a single medical centre were included in this study. Patients in other parts of rural Haryana may be having different prevalence of anaemia and different socio demographic factors contributing to the same. But such patients were not included in this study. Secondly, no interventions were planned or studied. So, further studies involving multiple centers are required to assess the actual extent of problem, factors responsible and measures required for the same.

\section{CONCLUSION}

There is a significantly high prevalence of anaemia among pregnant women in rural areas of Haryana. Our study has also enlisted a few socio demographic factors that contribute to such high prevalence of this disease. Programs focused on target population need to be planned and implemented with active participation of locals. Some of the interventions that can be done are screening programs for anaemia, awareness campaigns, frequent visits by anganwadi workers to pregnant women, cooking in iron utensils, fortification of food and salt with iron and folic acid, birth control for proper spacing of pregnancies, deworming of such patients. Such measures would go a long way in improving maternal and foetal outcome.

\section{Funding: No funding sources \\ Conflict of interest: None declared \\ Ethical approval: The study was approved by the Institutional Ethics Committee}

\section{REFERENCES}

1. Mayer EM, Tegman A. Prevalence of anaemia in the World. World Health Organ Qlty. 1998;38:302-16.

2. Ezzati M, Lopus AD, Dogers A, Vander HS, Murray C. Selected major risk factors and global and regional burden of disease. Lancet. 2002;360:134760.

3. USAID's A2Z micronutrient and child blindness project, ACCESS program, and food and nutrition technical assistance (FANTA) project. Maternal Anemia. 2006.

4. Levy A, Fraser D, Kartz M, Mazor M, Sheiner E. Maternal anaemia during pregnancy is an independent risk factor for low birth weight and pre mature delivery. Eur J Obstet Gynecol Reprod Biol. 2005;122(2):182-6.

5. Lone FW, Qureshi RN, Emanuel F. Maternal anaemia and its impact on perinatal outcome. Trop Med Int Health. 2004;9(4):486-90.

6. Zhang Q, Ananth CV, Rhoads GG, Li Z. The impact of maternal Anemia on perinatal mortality: a population-based, prospective cohort study in China. Annals Epidemiology. 2009;19(11):793-9.

7. Rusia U, Madan N, Agarwal N, Sikka M, Sood S. Effect of maternal iron deficiency anaemia on foetal outcome. Indian J Pathol Microbiol. 1995;38:273-9.

8. Stoltzfus RJ, Mullany L, Black RE. Iron deficiency anemia. In Ezzati M., Lopez A. D., Rodgers A., Murray CJL. editor. Comparative quantification of health risks: Global and regional burden of disease 
attributable to selected major risk factors. Geneva: World Health Organization. 2004;1:163-209.

9. The second National Family Health Survey (NFHS2). The database for implementation of the Reproductive and Child Health approach adopted by India. 1998-99.

10. National nutrition monitoring bureau (NNMB). NNMB micronutrient survey. Hyderabad: National Institute of Nutrition. 2002.

11. The 2005-06 National Family Health Survey (NFHS3). Series of national surveys. NFHS surveys: 199293 (NFHS-1) and 1998-99 (NFHS-2).

12. Toteja GS, Singh P. Micronutrient profile of Indian population. New Delhi. Indian Council of Medical Research. 2004:46.

13. International Institute of Population Sciences and Ministry of Health and Family Welfare, Government of India. Nutritional status of children and prevalence of anemia among children, adolescent girls and pregnant women. District Level Household Survey on Reproductive and Child Health, India, 2002-2004. Available at http:// www.rchiips.org/ pdf/ rch2/ National_Nutrition_Report_RCH-II.pdf. Accessed on 16 May 2015.

14. Statistics information, District Sonipat at a glance. Available at sonipat.nic.in/statistics.htm. Accessed on 16 May 2016.

15. Rajaratnam J, Abel R, Ganes C, Aseelan S. Maternal anaemia: a persistent problem in rural Tamil Nadu. National Med J India. 2000;13(5):242-5.

16. WHO SEARO. Control of iron deficiency anemia in South-East Asia. Report of an intercountry
Workshop. Salaya, Thailand. Institute Nutrition, Mahidol University. 1995:11-14.

17. Agarwal KN, Agarwal DK, Sharma A, Sharma K, Prasad K, Kalita MC, et al. Prevalence of anaemia in pregnant and lactating women in India. Indian J Med Res. 2006;124:173-84.

18. International Institute for Population Sciences (Deemed University) District Level Household and Facility Survey-4; State Fact Sheet Haryana. Mumbai:2012-13.Available at http:// www.http:// www.rchiips.org /pdf/dlhs4/report/HR.pdf. Accessed on 16 May 2015.

19. Kaur K. Anaemia 'a silent killer' among women in India: Present scenario. Euro J Zool Res. 2014;3(1):32-6.

20. Brabin L, Nicholas S, Gogate A, Gogate S, Karande A. High prevalence of anaemia among women in Mumbai, India. Food Nutrition Bull. 1998;19:205-9.

21. Thangleela T, Vijaylakshmi P. Prevalence of anemia in pregnancy. Indian J Nutrit Diet. 1994;31(2):26-9.

22. Dutta PK, Nagraj T, Gopinath VP. A case control study of anemia in pregnancy. Ind $\mathrm{J}$ Preventive Social Med. 1992;23(1):1-5.

23. Koen MC, Lemson MS, Kumar S, Abel R. Prevalence of anaemia among pregnant mothers in a rural south Indian population. J Obstet Gynecol India. 1992;42(6):283-7.

24. Bisoi S, Haldar D, Majumdar T, Bhattacharya N, Sarkar G, Ray S. Correlates of anemia among pregnant women in a rural area of West Bengal. Journal Family Welfare. 2011;57(1):72-8.

Cite this article as: Mangla M, Singla D. Prevalence of anaemia among pregnant women in rural India: a longitudinal observational study. Int J Reprod Contracept Obstet Gynecol 2016;5:3500-5. 